\title{
Hyperforin-Induced Activation of the Pregnane X Receptor Is Influenced by the Organic Anion-Transporting Polypeptide 2B1 ${ }^{\text {s }}$
}

\author{
Anima M. Schäfer, Olivier Potterat, Isabell Seibert, Orlando Fertig, \\ and Henriette E. Meyer zu Schwabedissen
}

\author{
Laboratories of origin: Biopharmacy (A.M.S., I.S., H.E.M.z.S.) and Pharmaceutical Biology (O.P., O.F.), Department \\ Pharmaceutical Sciences, University of Basel, Basel, Switzerland
}

Received August 21, 2018; accepted December 17, 2018

\begin{abstract}
The herbal remedy St. John's wort (SJW) is used in the treatment of mild depressive symptoms and is known for its drug-drug interaction potential when enhanced expression of CYP3A4 modifies clearance of concomitantly applied substrate drugs. Hyperforin is one constituent of SJW that alters CYP3A4 expression by activation of the nuclear receptor pregnane $X$ receptor (PXR). However, little is known about the transmembrane transport of hyperforin. One membrane protein that modulates cellular entry of drugs is the organic aniontransporting polypeptide (OATP) 2B1. It was the aim of this study to test whether hyperforin interacts with this transport protein. Transport inhibition studies and competitive counterflow experiments suggested that hyperforin is a substrate of OATP2B1. This notion was validated by showing that the presence of OATP2B1 enhanced the hyperforin-induced PXR
\end{abstract}

activation in cell-based luciferase assays. Moreover, in Caco-2 cells transcellular transport of the known OATP2B1 substrate atorvastatin was changed in the presence of hyperforin, resulting in an increased efflux ratio. Eleven commercially available SJW formulations were assessed for their influence on OATP2B1mediated transport of estrone 3-sulfate and for their impact on CYP3A4 promoter transactivation. The correlation between effect size and the hyperforin content as determined by highperformance liquid chromatography with ultraviolet detection suggested that hyperforin is the major determinant. Our results indicate an interaction between hyperforin and OATP2B1, which is not only known to contribute to hepatocellular uptake but also to intestinal absorption of its substrates. These findings extend the complexity of mechanisms that should be considered when evaluating the interaction potential of SJW preparations.

\section{Introduction}

St. John's wort is an herbal extract of Hypericum perforatum and is commonly taken to treat depressive symptoms. The extract is a complex mixture of structurally diverse constituents, including flavonol glycosides, phloroglucinols, proanthocyanidins, naphthodianthrones, and phenylpropanoids (Nahrstedt and Butterweck, 1997). The naphthodianthrones pseudohypericin and hypericin were originally assumed to be the active components of Hypericum extracts (Suzuki et al., 1984). Accordingly, hypericin became the constituent on which therapeutically used extracts are standardized. However, even though the antidepressive activity is still not fully understood, more recent studies suggest that it is most probably linked to the phloroglucinol hyperforin. (Mennini and Gobbi, 2004).

Beside its antidepressant activity, St. John's wort is known for its pronounced influence on expression and activity of genes involved in drug metabolism (Soleymani et al., 2017). Indeed, hyperforin enhances expression and activity of

This work was conducted without support by external funding agencies. None of the authors has a conflict of interest to declare.

https://doi.org/10.1124/mol.118.114066.

S This article has supplemental material available at molpharm. aspetjournals.org.
CYP3A4, thereby modifying the first-pass metabolism and clearance of concomitantly applied substrates (Wang et al., 2013). Similar results were shown for the efflux transporter P-glycoprotein (P-gp, ABCB1, MDR1), when treatment with St. John's wort extracts increased intestinal ABCB1 expression, explaining the reduced bioavailability of $\mathrm{ABCB} 1$ substrates (Dürr et al., 2000). The underlying mechanism is the activation of the pregnane X receptor (PXR) (Kliewer et al., 2002). PXR is a nuclear receptor functioning as ligand-activated transcription factor of a gene network comprising various proteins involved in drug metabolism, including CYP3A4 (Lehmann et al., 1998), the efflux transporter P-gp (Geick et al., 2001), the multidrugresistance protein 3 (ABCC3, MRP3) (Aleksunes and Klaassen, 2012), the organic anion-transporting polypeptide (OATP) 1A2 (Meyer zu Schwabedissen et al., 2008), the UDPglucuronosyltransferase 1a5 (Ugt1a5), and the sulfotransferase 2a2 (Sult2a2) (Aleksunes and Klaassen, 2012). Accordingly, PXR activation in general results in enhanced metabolic activity and increased metabolic clearance. Hyperforin, even if very potent, is not the only activator of PXR, since multiple drugs in clinical use function as activating ligands (Meyer zu Schwabedissen and Kim, 2009). Accordingly, PXR is also called a xenosensor as it senses drug exposure and modulates metabolic activity in response. There are multiple examples

ABBREVIATIONS: BSP, bromosulfophthalein; CCF, competitive counterflow; $\mathrm{E}_{1} \mathrm{~S}$, estrone 3-sulfate; HPLC, high-performance liquid chromatography; MDCKII cells, Madin-Darby canine kidney epithelial cells; MRP, multidrug resistance-associated protein; OATP, organic aniontransporting polypeptide; PBS, phosphate-buffered saline; PXR, pregnane X receptor; SJW, St. John's wort. 
in the literature in which PXR activation is the basis of observed drug-drug interactions, e.g., simultaneous administration of indinavir and St. John's wort reduces exposure of the protease inhibitor (Piscitelli et al., 2000). Additionally, Ruschitzka et al. (2000) reported heart transplant rejections in patients concomitantly treated with cyclosporine and St. John's wort. The authors report reduced oral bioavailability and increased hepatic clearance of the victim drug. Importantly, to interact with PXR and to activate transcription of the targeted genes, hyperforin has to enter the cell. So far, little is known about the transmembrane transport and cellular uptake of this molecule.

Recent findings by our group suggest that hyperforin is a substrate of OATP2B1, as was observed by testing whether the method of competitive counterflow (CCF) can be applied to identify substrates of this uptake transporter (Schäfer et al., 2018). OATP2B1 is a member of the organic anion-transporting polypeptide family, and facilitates the sodium-independent uptake of its substrates. Since its first description (Tamai et al., 2000) multiple endogenous and exogenous substrates of the transporter have been identified (Roth et al., 2012). OATP2B1 exhibits two substrate binding sites that can be distinguished in experimental setting by their contribution to the cellular uptake of estrone 3 -sulfate $\left(\mathrm{E}_{1} \mathrm{~S}\right)$; one accepts $\mathrm{E}_{1} \mathrm{~S}$ at low concentration (binding site $\mathrm{A}$ ), whereas the other (binding site B) mainly drives uptake at high concentrations of the sulfated steroid (Shirasaka et al., 2012). Another characteristic of OATP2B1 is its ubiquitous expression, with high amounts of the transporter in brain, heart, kidney, lung, mammary gland, placenta, platelets, skeletal muscle and skin (St-Pierre et al., 2002; Pizzagalli et al., 2003; Schiffer et al., 2003; Bronger et al., 2005; Grube et al., 2006; Niessen et al., 2009; Knauer et al., 2010; Sakamoto et al., 2013; Ferreira et al., 2018). Considering the abovementioned impact of PXR on hepatic clearance and oral bioavailability, it seems noteworthy that OATP2B1 is expressed in the sinusoidal membrane of hepatocytes (Kullak-Ublick et al., 2001) and in the intestine (Kobayashi et al., 2003; Keiser et al., 2017), thereby contributing to hepatic clearance and intestinal absorption, respectively. Even if several drug transporters are part of the PXR-regulated gene network, OATP2B1 is not (Knauer et al., 2013; Meyer zu Schwabedissen et al., 2018). However, our preliminary findings (Schäfer et al., 2018) suggest that drugdrug interactions involving hyperforin may not be limited to targets of PXR but may also involve OATP2B1-mediated uptake. It was the aim of the present study to further evaluate this notion.

\section{Materials and Methods}

Cell Culture. All cell lines were maintained at $37^{\circ} \mathrm{C}$ in a humidified atmosphere with $5 \% \mathrm{CO}_{2}$. The cell lines Madin-Darby canine kidney epithelial cells (MDCKII; ATCC no. CRL-2936), HeLa (ATCC no. CCL2), HepG2 (ATCC no. HB-8065), and Caco-2 (ATCC no. HTB37) were originally obtained from the American Type Culture Collection (ATCC, Wesel, Germany) and were cultured in Dulbecco's modified Eagle's medium (DMEM; Sigma-Aldrich, Buchs, Switzerland) supplemented with $10 \%$ fetal calf serum (Sigma-Aldrich) and 1\% stable glutamine (BioConcept, Basel, Switzerland). For Caco-2 cells the medium was supplemented with $1 \%$ penicillin/streptomycin (BioConcept, Basel, Switzerland). MDCKII-OATP2B1 cells have been established and characterized as described elsewhere (Grube et al., 2006) and were kept under continuous selection with $750 \mu \mathrm{g} / \mathrm{ml}$ hygromycin B (Carl Roth, Karlsruhe, Germany).
Transport Experiments. MDCKII-OATP2B1 cells were seeded in 24-well plates at a density of 50,000 cells/well (Eppendorf, Hamburg, Germany). After 1 day in culture, cells were treated with sodium butyrate $(2 \mathrm{mM})$ and cultured for an additional day. Uptake experiments were started by washing the cells with prewarmed phosphate-buffered saline (PBS) followed by a 10-minute equilibration with Hanks' balanced salt solution (H8264, with sodium bicarbonate, without phenol red, $\mathrm{pH}$ 7.4; Sigma-Aldrich). To test the inhibitory potency of hyperforin (as hyperforin dicyclohexylammonium salt; Sigma-Aldrich) and hypericin (Tocris, Bio-Techne AG, Zug, Switzerland) cells were exposed to either estrone 3 -sulfate $(0.005$ or $50 \mu \mathrm{M}$; Sigma-Aldrich) or $0.1 \mu \mathrm{M}$ bromosulfophthalein (BSP; SigmaAldrich), supplemented with $50,000 \mathrm{dpm} /$ well of $\left[{ }^{3} \mathrm{H}\right]-\mathrm{E}_{1} \mathrm{~S}(3 \mathrm{nM}$; Hartmann Analytic, Braunschweig, Germany), or [ $\left.{ }^{3} \mathrm{H}\right]-\mathrm{BSP}$ (9 nM; Hartmann Analytic) in the presence of different concentrations of the respective compound. After 5 minutes of exposure the cells were washed with ice-cold PBS, lysed in $200 \mu \mathrm{l}$ of $0.2 \%$ SDS- $5 \mathrm{mM}$ EDTA, and the cellular content of $\mathrm{E}_{1} \mathrm{~S}$ or BSP was quantified determining the amount of tracer by liquid scintillation counting using the Rotiszint eco Plus (Carl Roth) and the Tri-Carb 2900TR counter (TopLab, Basel, Switzerland). An aliquot was used to assess the amount of protein in each well using the Pierce BCA Protein Assay Kit (Thermo Fisher Scientific, Reinach, Switzerland) and the microplate reader Infinite 200 Pro (Tecan, Männedorf, Switzerland). CCF experiments were performed as previously described by our group (Schäfer et al., 2018). MDCKII-OATP2B1 and MDCKII cells were seeded, treated, and prepared for transport experiments as described above. Since $\mathrm{CCF}$ experiments are conducted in the steady state, cells were preincubated with $\left[{ }^{3} \mathrm{H}\right]-\mathrm{E}_{1} \mathrm{~S}(100,000 \mathrm{dpm} /$ well $)$ for 30 minutes. For a time-dependent CCF experiment in MDCKII-OATP2B1 cells, the supernatant was exchanged to either $\left[{ }^{3} \mathrm{H}\right]-\mathrm{E}_{1} \mathrm{~S}$ alone or supplemented with hyperforin $(5 \mu \mathrm{M})$ or hypericin $(100 \mu \mathrm{M})$. Cellular accumulation of $\left[{ }^{3} \mathrm{H}\right]-\mathrm{E}_{1} \mathrm{~S}$ was measured as described above after 10 , $20,30,45,60,90,120$, and 180 seconds. Since the system was equilibrated again after 90 seconds, this was defined as the time point when intracellular accumulation of $\left[{ }^{3} \mathrm{H}\right]-\mathrm{E}_{1} \mathrm{~S}$ was measured in CCF experiments. MDCKII-OATP2B1 and MDCKII cells were treated with $\left[{ }^{3} \mathrm{H}\right]-\mathrm{E}_{1} \mathrm{~S}$ until steady state before medium was changed to the same concentration of $\left[{ }^{3} \mathrm{H}\right]-\mathrm{E}_{1} \mathrm{~S}$ supplemented with hyperforin, hypericin, atorvastatin (2.5 $\mu \mathrm{M}$; Sigma-Aldrich) as positive, and penicillin G (250 $\mu \mathrm{M}$; Sigma-Aldrich) as negative control. For inhibition studies, $2.5 \mu \mathrm{M}$ atorvastatin supplemented with 50,000 $\mathrm{dpm} / \mathrm{well}\left[{ }^{3} \mathrm{H}\right]$-atorvastatin (7.5 nM; PerkinElmer, Waltham, MA) was used. Cellular accumulation after 5 minutes of exposure was assessed in presence of different concentrations of hyperforin $(0.1,1,5 \mu \mathrm{M})$ or hypericin $(10,50,100 \mu \mathrm{M})$.

Cell-Based Reporter Gene Assays. The previously reported CYP3A4-XREM-pGL3 plasmid was used to test the influence of OATP2B1 on PXR-mediated transactivation. Briefly, HepG2 and HeLa cells were seeded in 24-well plates at a density of 50,000 cells/well. The cells were then transfected with $250 \mathrm{ng}$ of CYP3A4XREM-pGL3 (Tirona et al., 2003), $25 \mathrm{ng}$ of pRL-TK, $250 \mathrm{ng}$ of PXRpEF6 (Meyer zu Schwabedissen et al., 2008), $250 \mathrm{ng}$ of RXR $\alpha$-pEF6), $250 \mathrm{ng}$ of OATP2B1-pEF6, or $250 \mathrm{ng}$ of pEF6-V5/HIS as control (Thermo Fisher Scientific), using $2.25 \mu \mathrm{l} / \mu \mathrm{g}$ of DNA jetPRIME (Polyplus distributed by Chemie Brunschwig, Basel, Switzerland). After 4 hours, the medium was changed, and the cells were kept in culture until treatment started 24 hours after transfection. Hyperforin, hypericin, bromosulfophthalein, and rifampicin were used at a final concentration of $0.1,1,10$, and $10 \mu \mathrm{M}$, respectively. The formulations were tested at a $1 / 100$ dilution of one tablet or capsule dissolved in $200 \mathrm{ml}$. To avoid phototoxicity the experiment was performed in the dark. Finally, the cells were lysed after 24 hours of exposure and luciferase activity was determined using the DualLuciferase Assay System (Promega, Dübendorf, Switzerland) and the plate reader Infinite M200 Pro (Tecan) as recommended by the manufacturer. The observed activity of the firefly luciferase was normalized to that of the Renilla. 
Transwell Transport of Hyperforin and Hypericin. Experiments were performed as previously described (Meyer zu Schwabedissen et al., 2018). Briefly, Caco-2 cells were seeded at a density of $3 \times 10^{5}$ cells/well onto polycarbonate membranes with $0.4-\mu \mathrm{m}$ pore size inserted in 12-well plates (Chemie Brunschwig, Basel, Switzerland) and cultivated for 14 days with medium change every second day. Measuring the transepithelial electrical resistance value of at least $200 \Omega / \mathrm{cm} 1$ day before the experiment confirmed the integrity of the monolayer. Furthermore, integrity was tested after the experiment by addition of $1 \mathrm{mg} / \mathrm{ml}$ Lucifer yellow (Sigma-Aldrich) to the apical side and measurement of absorbance in the basolateral compartment after 1 hour by spectrofluorometry. On the day of the experiment, cells were washed once with prewarmed PBS before incubation with Krebs-Henseleit buffer $\left(118 \mathrm{mM} \mathrm{NaCl}, 25 \mathrm{mM} \mathrm{NaHCO}_{3}\right.$, $1.2 \mathrm{mM} \mathrm{KH}_{2} \mathrm{PO}_{4}, 2.5 \mathrm{mM} \mathrm{CaCl}_{2}, 1.2 \mathrm{mM} \mathrm{MgSO}_{4}, 11 \mathrm{mM}$ glucose, $4.7 \mathrm{mM}$ $\mathrm{KCl}$ ) for 20 minutes at $37^{\circ} \mathrm{C}$. The buffer was adjusted to a $\mathrm{pH}$ of 5.5 in the apical compartment and to a $\mathrm{pH}$ of 7.4 in the basolateral compartment. $\left[{ }^{3} \mathrm{H}\right]$-Atorvastatin $(100,000 \mathrm{dpm} /$ well $)$ was added either to the apical or to the basolateral side to determine apical to basal (a-b) or basal to apical (b-a) permeability. Hyperforin $(0.1 \mu \mathrm{M})$ was added to either the apical or the basal compartment. Amount of atorvastatin was assessed in 100- $\mu$ l aliquots by scintillation counting as described above. The amount of transported $\left[{ }^{3} \mathrm{H}\right]$-atorvastatin per time was calculated as permeability coefficient $\left(\mathrm{P}_{a p p}\right)$ as previously described (Hubatsch et al., 2007). $\mathrm{P}_{a p p}$ of the apical (a)-to-basal (b) or of the b-to-a direction was used to calculate the uptake and efflux ratio, respectively, with the following equations:

$$
\text { uptakeratio } P_{\mathrm{a}-\mathrm{b}}=\frac{\mathrm{P}_{a p p}(\mathrm{a} \text { to } \mathrm{b})}{\mathrm{P}_{a p p}(\mathrm{~b} \text { to } \mathrm{a})} \quad \text { effluxratio } P_{\mathrm{b}-\mathrm{a}}=\frac{\mathrm{P}_{a p p}(\mathrm{~b} \text { to } \mathrm{a})}{\mathrm{P}_{a p p}(\mathrm{a} \text { to } \mathrm{b})}
$$

Transport Studies with 11 Swiss Formulations Containing St. John's Wort. Before transport experiments, pills were milled using the mixer mill MM 400 (Retsch GmbH, Haan, Germany) or capsules were opened to release the content. The concentration for inhibition experiments was estimated by calculating the expected concentration in the intestine when the pill or capsule would be ingested with $200 \mathrm{ml}$ water. Two days before the experiment MDCKIIOATP2B1 cells were seeded as described above. After washing the cells with PBS and a 10-minute preincubation in Hanks' balanced salt solution buffer, influence was tested by treating the cells with 0.005 $\mu \mathrm{M} \mathrm{E}_{1} \mathrm{~S}$ supplemented with radiolabeled $\mathrm{E}_{1} \mathrm{~S}(50,000 \mathrm{dpm} / \mathrm{well})$ and the respective formulation diluted 1:100 and 1:1000. After 5 minutes, cells were washed with ice-cold PBS and lysed in $200 \mu \mathrm{l}$ of $0.2 \%$ SDS-5 mM EDTA. Protein amount and intracellular accumulation of $\left[{ }^{3} \mathrm{H}\right]-\mathrm{E}_{1} \mathrm{~S}$ was measured as described in detail above.

Western Blot Analysis. HepG2 and HeLa cells were seeded at a density of $1.8 \times 10^{6}$ cells/10-cm culture dish (Eppendorf). After reaching confluence, cells were harvested in $5 \mathrm{mM}$ Tris- $\mathrm{HCl}$ ( $\mathrm{pH}$ 7.4) supplemented with the protease inhibitor cocktail (Sigma-Aldrich). After several cycles of freezing and thawing, protein content in the cell lysate was quantified using the Pierce BCA Protein Assay Kit (Thermo Fisher Scientific). Proteins were separated by SDS-PAGE (Mini-PROTEAN System) followed by blotting onto a nitrocellulose membrane with the Mini Trans-blot Cell (Bio-Rad Laboratories AG, Cressier, Switzerland). Fetal calf serum (5\%)-Tris-buffered saline-0.04\% Tween 20 (TBS-T) was used to block unspecific binding before the primary antibody anti-HNF $4 \alpha$ (ab41898; Abcam, Lucerna Chem AG, Luzern, Switzerland, diluted 1:1000) or anti-OATP2B1 [(Grube et al., 2005) diluted 1:5000] was added and incubated at $4^{\circ} \mathrm{C}$ overnight. Actin (sc-1616, diluted 1:1000; Santa Cruz Biotechnology, Heidelberg, Germany) served as control. HRPlabeled secondary antibodies and the ECL Western blotting substrate (Pierce/Thermo Fisher Scientific) were used to detect binding of the primary antibody. The Chemidoc XRS System (Bio-Rad Laboratories AG) was used for visualization and digitization of chemiluminescence.

Determination of Hyperforin and Hypericin Content in 11 Swiss Formulations with High-Performance Liquid Chromatography. One-hundred milligrams of the powdered samples was dissolved in $1 \mathrm{ml}$ of DMSO and centrifuged at 13,000 rpm for 5 minutes before filtration through a disposable syringe filter (Micropur PTFE, pore-size: $0.45-\mu \mathrm{m}$, Altmann Analytik, Munich, Germany). Dissolution of the solid residue of Deprivita, Hyperiplant, Rebalance, Sandoz Hypericum, and Vogel Hyperiforce using the same procedure confirmed $>80 \%$ and $>90 \%$ dissolution of hypericin and hyperforin, respectively. Hypericin was TOCRIS brand and had $>98 \%$ purity according to manufacturer. A calibration curve was prepared with a hypericin dilution ranging from 1 to $0.002 \mathrm{mg} / \mathrm{ml}$. The hypericin calibration curve was also used for the simultaneous quantification of pseudohypericin since both compounds have the same chromophore. The identity of pseudohypericin was confirmed by chromatographic comparison with a reference sample purchased from Sigma-Aldrich. The content of hypericin was calculated as the sum of the content of hypericin and pseudohypericin. Hyperforin was purchased from SigmaAldrich as dicyclohexylammonium salt. According to the manufacturer, purity was $98 \%$ as a mixture of hyperforin and adhyperforin. Considering that both compounds have the same chromophore and taking into account their respective molecular weights, the commercial sample was determined by high-performance liquid chromatography with UV detection (HPLC-UV) to contain $83.6 \%$ hyperforin and $16.4 \%$ adhyperforin. Two calibration curves were therefore prepared for hyperforin $(0.9-0.007 \mathrm{mg} / \mathrm{ml})$ and adhyperforin $(0.18-0.0014 \mathrm{mg} / \mathrm{ml})$ and the content of hyperforin was calculated as the sum of both phloroglucinols. Since hyperforin is highly sensitive to light and oxygen all preparatory steps for measuring hyperforin content were performed under exclusion of light. Prior to grinding and solving of the samples, the respective tubes were prefilled with nitrogen to avoid oxidation. HPLC analyses were performed on an Alliance 2690 chromatographic system coupled to a PDA996 detector (Waters, Milford, MA). The mobile phase consisted of water (A) and acetonitrile (B) both containing $0.1 \%$ trifluoroacetic acid (hyperforin analysis) or $0.5 \%$ trifluoroacetic acid (hypericin analysis). Separation of hyperforin was achieved using a 115 Zorbax Eclipse XDB-C8 Narrow-Bore column $(2.1 \times 150 \mathrm{~mm}, 3.5 \mu \mathrm{m}$; Agilent, Santa Clara, CA) with a gradient of $50 \%-100 \%$ B in 20 minutes, then $100 \%$ B for 15 minutes at a flow rate of $0.4 \mathrm{ml} /$ minute. Hypericin was analyzed on an Ascentis Express C18 column $(3 \times 100 \mathrm{~mm}, 2.7 \mu \mathrm{m}$; Supelco, Bellefonte, PA) with a gradient of $45-100 \%$ in 15 minutes, then $100 \%$ $\mathrm{B}$ for 5 minutes at a flow rate of $0.6 \mathrm{ml} /$ minute. The injection volume was $10 \mu \mathrm{l}$ for the calibrators and the formulation samples. Detection was at $272 \mathrm{~nm}$ (hyperforin) or $588 \mathrm{~nm}$ (hypericin). Separations were performed at $30^{\circ} \mathrm{C}$. Data are reported as mean \pm S.D. of three independent analyses.

Statistical Analysis. Microsoft Excel (Microsoft, Redmond, USA) and GraphPad Prism software 6.0 (GraphPad Software, La Jolla, CA) was used to analyze the data sets reported herein. Tests used for statistical analysis are described in the context of data presentation. A $P$-value below 0.05 was considered statistically significant.

\section{Results}

Interaction of Hyperforin and Hypericin with OATP2B1-Mediated Uptake. To validate the interaction of hyperforin and hypericin with OATP2B1, their impact on the cellular accumulation of the known substrates estrone 3-sulfate (Pizzagalli et al., 2003) and bromosulfophthalein (Kullak-Ublick et al., 2001) was determined in MDCKIIOATP2B1 cells. As shown in Fig. 1 the estrone 3-sulfate inhibition studies accounted for the previously reported two binding sites (Shirasaka et al., 2012) testing the influence of hyperforin and hypericin on estrone 3 -sulfate accumulation at low (Fig. 1, A and D; representing binding site A) and at high concentrations (Fig. 1, B and E, representing binding site B). For hyperforin, we observed concentration-dependent inhibition for both binding sites recognizing $\mathrm{E}_{1} \mathrm{~S}$. The inhibition data were the basis for an estimation of the respective $\mathrm{IC}_{50}$ values, which revealed the highest potency for binding site 
A-mediated transport of $\mathrm{E}_{1} \mathrm{~S}$, with an $\mathrm{IC}_{50}$ value of $0.32 \mu \mathrm{M}(\mathrm{CI}$ $0.24-0.42 \mu \mathrm{M}$, Fig. $1 \mathrm{~A}$ ), whereas for binding site $\mathrm{B}$ the $\mathrm{IC}_{50}$ value was $5.55 \mu \mathrm{M}$ (CI 2.10-14.73 $\mu \mathrm{M}$, Fig. 1B). Inhibition of OATP2B1-mediated cellular accumulation of BSP resulted in an estimated $\mathrm{IC}_{50}$ value for hyperforin of $0.82 \mu \mathrm{M}$ (CI $0.53-$ $1.26 \mu \mathrm{M}$, Fig. 1C). Similar results were obtained for hypericin, even if this compound exhibited much lower $\mathrm{IC}_{50}$ values for binding site A (20.79 $\mu \mathrm{M}$; CI 13.90-31.10 $\mu \mathrm{M}$, Fig. 1D), binding site B $256.2 \mu \mathrm{M}$ (CI 119.4-550.0 $\mu \mathrm{M}$, Fig. 1E), and for BSP (108.7 $\mu \mathrm{M}$ (CI 76.39-154.8 $\mu \mathrm{M}$, Fig. 1F). To test whether hyperforin and hypericin are also substrates of OATP2B1 we applied the method of competitive counterflow. The basis of the experimental procedure used to identify substrates competing for substrate recognition is depicted in Fig. 1G. Briefly, interaction with the transporter is assessed in the steady state. Reduction of the intracellular estrone 3 -sulfate amount in the equilibrium would be attributable to competitive inhibition, showing that the test compound is a substrate of the facilitating mechanism, whereas inhibitors would not influence the cellular equilibrium (Harper and Wright, 2013). As shown in Fig. 1H, presence of the known OATP2B1 substrate atorvastatin, as well as hyperforin $(5 \mu \mathrm{M})$ or hypericin $(100 \mu \mathrm{M})$, reduced the amount of $\mathrm{E}_{1} \mathrm{~S}$ in the steady state $(P<0.05)$, thereby suggesting that both constituents of St. John's wort are not only inhibitors but also substrates of OATP2B1. Penicillin G served as nonsubstrate control (Schäfer et al., 2018). In the CCF experiments in MDCKII cells, no influence on the cellular amount of $E_{1} S$ was observed for any of the compounds tested herein (Supplemental Fig. 1). Assessing the time-dependency of reaching the second equilibrium for hyperforin (Supplemental Fig. 2A) and hypericin (Supplemental Fig. 2B) revealed that it is reached after 90 seconds of exposure, which is comparable to that previously reported (Schäfer et al., 2018).

Influence of OATP2B1 on Hyperforin-Mediated Transactivation of CYP3A4. Hyperforin is a well known ligand and activator of the human pregnane $\mathrm{X}$ receptor, which thereby influences transcription of CYP3A4 (Moore et al., 2000). To verify that hyperforin is a substrate of OATP2B1, we deployed cell-based reporter gene assays to assess the transactivation of a synthetic CYP3A4-XREM-pGL3 reporter gene construct. As shown in Fig. 2A, HepG2-cells transfected with PXR- and OATP2B1-pEF6 exhibited higher luciferase activation $(P<0.05)$ than cells not heterologously expressing the transporter. Testing the influence of $10 \mu \mathrm{M}$ BSP on hyperforin-induced $(0.1 \mu \mathrm{M})$ PXR-mediated transactivation of CYP3A4 in OATP2B1-overexpressing cells showed that presence of this competitive inhibitor of the transporter reduced luciferase activity statistically significantly. Importantly, BSP did not influence the luciferase activity (Fig. 2B).

Impact of Hyperforin and Hypericin on Transcellular Fluxes in Caco-2 Cells. Expression of OATP2B1 is assumed to contribute to intestinal absorption of orally applied drugs. Transcellular flux experiments using the intestinal model cell line Caco-2 cells are often applied in the preclinical phase to not only predict bioavailability but also to determine whether there is an active transport component influencing the transcellular path of a new molecular entity. OATP2B1 is expressed in Caco-2 cells and is part of the network of transporters influencing the transcellular flux (Meyer zu Schwabedissen et al., 2018). To determine whether hyperforin influences transcellular fluxes, and thereby oral bioavailability, experiments were performed using the known OATP2B1 substrate drug atorvastatin (Grube et al., 2006). At first, interaction of hyperforin with OATP2B1-mediated atorvastatin uptake was tested (Fig. 3A), revealing a decreased amount of intracellular atorvastatin with increasing concentrations $(P<0.05)$. As controls, $\mathrm{BSP}$ and $\mathrm{E}_{1} \mathrm{~S}$ were included in the transport inhibition study. Estimation of the inhibitory potency, even though a limited number of data points was used as a basis, suggested an $\mathrm{IC}_{50}$ value for hyperforin of $0.23 \mu \mathrm{M}(\mathrm{CI} 0.11-0.48 \mu \mathrm{M})$. As shown in Fig. 3B, hyperforin increased the efflux ratio observed for atorvastatin (mean efflux ratio \pm S.D.; hyperforin vs. DMSO; $2.863 \pm 0.415$ vs. $1.828 \pm 0.332 ; P=0.028$ ). The observed effect can mainly be attributed to changes in the flux from apical (a) to basal (b), as there was a trend toward lower movement in this direction [mean $\mathrm{P}_{\mathrm{app}}(\mathrm{a}-\mathrm{b}) \pm \mathrm{S} . \mathrm{D} .(\mathrm{cm} / \mathrm{s})$; hyperforin vs. DMSO; $1.33 \times$ $10^{-6} \pm 3.161 \times 10^{-7}$ vs. $1.83 \times 10^{-6} \pm 2.621 \times 10^{-7} ; P=0.103$, Fig. 3C)]. No trend for a change was observed for the atorvastatin flux in $\mathrm{b}$ to a direction [mean $\mathrm{P}_{\mathrm{app}}(\mathrm{b}-\mathrm{a}) \pm$ S.D. $(\mathrm{cm} / \mathrm{s})$; hyperforin vs. DMSO $3.81 \times 10^{-6} \pm 1.153 \times 10^{-6} \mathrm{vs}$. $3.36 \times 10^{-6} \pm 8.502 \times 10^{-7} ; P=0.615$, Fig. 3D]. Taken together these data suggest that hyperforin interacts with intestinal absorption of atorvastatin, which is in part mediated by OATP2B1.

Effect of St. John's Wort Formulations on OATP2B1Mediated Transport. St. John's wort is widely used as medication to treat mild to moderate depression. In Switzerland there are currently 11 solid formulations marketed. These formulations contain different amounts of hypericin and hyperforin as reported by the manufacturer and summarized in Table 1. In a screening experiment, we tested for interaction of the formulations with OATP2B1-mediated $\mathrm{E}_{1} \mathrm{~S}$ uptake in MDCKII-OATP2B1 cells. This screening was conducted using two concentrations of the respective formulation, representing a $1 / 100$ or $1 / 1000$ dilution of one tablet or capsule dissolved in $200 \mathrm{ml}$ of liquid. As shown in Fig. 4A, none of the 1/1000 dilutions lowered the cellular accumulation of $\mathrm{E}_{1} \mathrm{~S}$ compared with solvent control $(P>0.05)$. However, for the formulations Arkocaps, Deprivita, Hänseler Menopause, Hyperiplant, Jarsin, Sandoz Hypericum, and Solevita, we observed reduced OATP2B1-mediated uptake of estrone 3-sulfate for the 1/100 dilution $(P<0.05)$. Rebalance, Remotiv, Vogel Hyperimed, and Vogel Hyperiforce did not affect OATP2B1-mediated $\mathrm{E}_{1} \mathrm{~S}$ uptake in our experiments.

Subsequently, we assessed the influence of the respective formulation on the PXR-mediated transactivation of CYP3A4 either in HepG2 (Fig. 4B), or HeLa (Fig. 4C). Notably, in accordance with our transport inhibition experiments, Rebalance, Remotiv, Vogel Hyperimed, and Vogel Hyperiforce did not affect luciferase activation in either cell-based reporter gene assay $(P>0.05)$. Interestingly, treatment of HepG2 cells resulted in an up to 125 -fold induction in presence of a $1 / 100$ dilution of the formulations, whereas a maximum of about 7-fold induction was observed in HeLa cells. This might be explained by the endogenous expression of $\mathrm{HNF} 4 \alpha$, which is permissive for the transactivation of CYP3A4 by PXR (Tirona et al., 2003). The lack of HNF $4 \alpha$ expression in HeLa cells was verified by Western blot analysis (Fig. $4 \mathrm{D}$; mean $\mathrm{HNF} 4 \alpha$ expression normalized to actin \pm S.D.; HepG2 vs. HeLa; 17.88 \pm 3.43 vs. $0.26 \pm 0.02 ; P<0.05, n=3$, unpaired $t$ test with Welch's correction), whereas no difference in expression of OATP2B1 was observed (Fig. 4E; mean OATP2B1 expression 
A

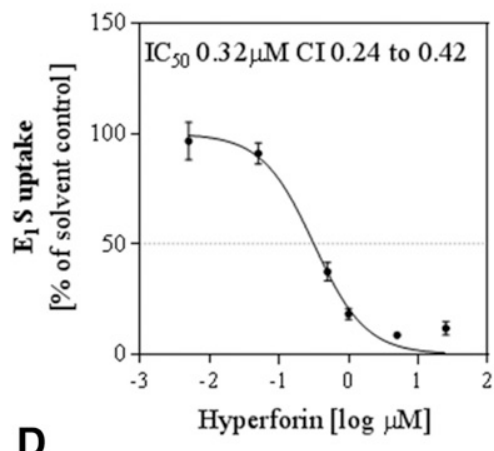

D

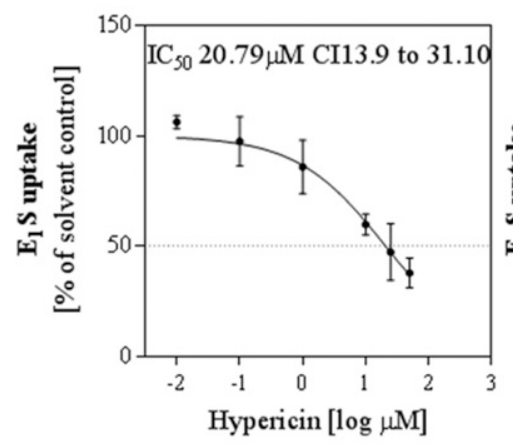

G
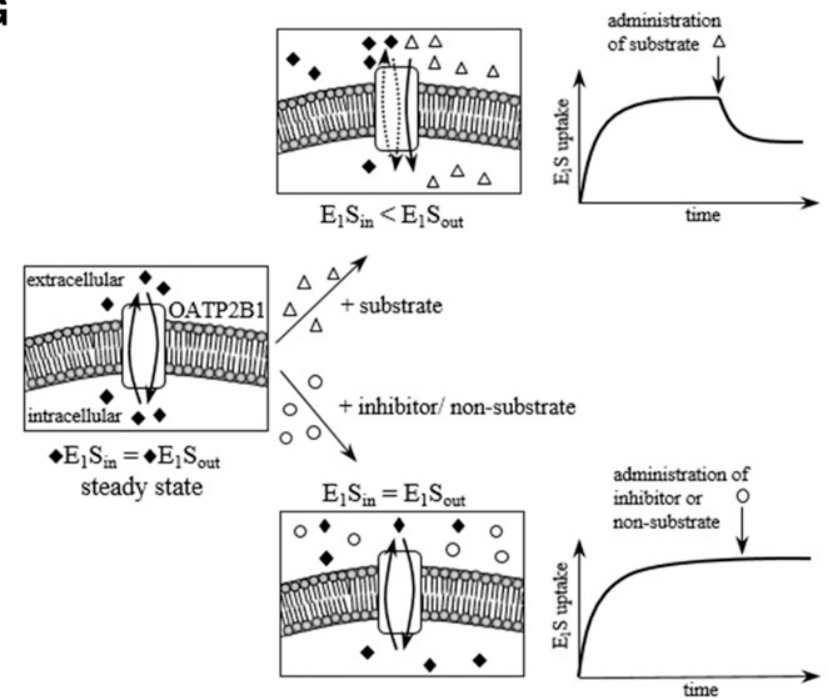

C

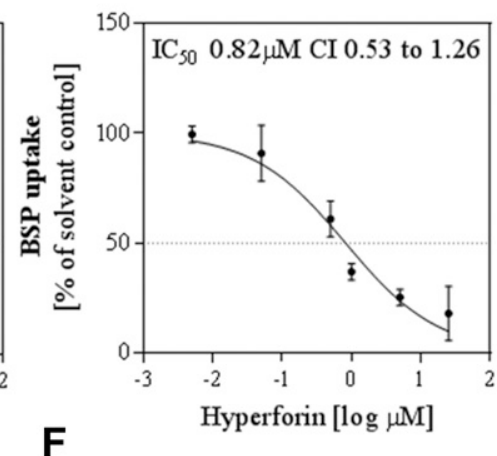

F

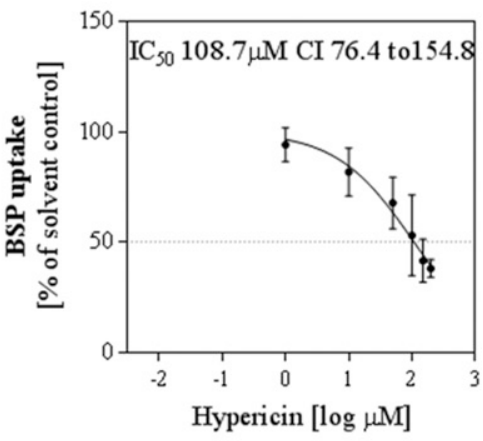

H

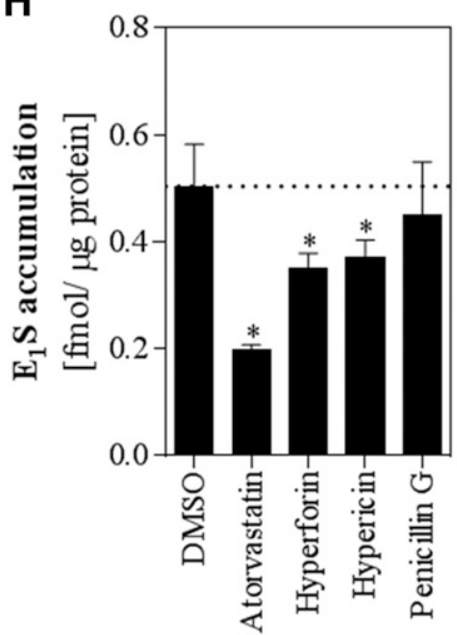

Fig. 1. Interaction of hyperforin and hypericin with OATP2B1. Inhibition of OATP2B1-mediated transport by hyperforin and hypericin was tested in MDCKII-OATP2B1 cells. The influence on cellular accumulation of estrone 3-sulfate was determined at low (0.005 $\mu \mathrm{M} ; \mathrm{A}$ and D) or high (50 $\mu \mathrm{M}$; B and E) concentration to account for binding site $\mathrm{A}$ or $\mathrm{B}$, respectively, or of bromosulfophthalein $(\mathrm{C}$ and $\mathrm{F})$. The $\mathrm{IC}_{50}$ values were calculated fitting the data to a sigmoidal $\log$ (inhibitor)-normalized response curve, without constraining of top or bottom, or weighting. (G) Schematic of the molecular basis of competitive-counterflow experiments, in which substrates are reduced by the amount of another substrate in the steady state. Tested was the influence of hyperforin or hypericin on the cellular equilibrium of $\mathrm{E}_{1} \mathrm{~S}$ in MDCKII-OATP2B1 cells compared with DMSO control $(\mathrm{H})$. Atorvastatin and penicillin $\mathrm{G}$ were used as positive and negative controls, respectively. Data are presented as mean \pm S.D. of $n=3$ independent experiments, each performed in biologic triplicates. $* P \leq 0.05$, one-way analysis of variance with Dunnett's multiple comparisons test.

normalized to actin \pm S.D.; HepG2 vs. HeLa; $1.52 \pm 1.28$ vs. $1.41 \pm 0.72 ; P>0.05, n=3$, unpaired $t$ test with Welch's correction).

Quantification of Hyperforin and Hypericin Content in the St. John's Wort Formulations. As mentioned before, most manufacturers merely provide information on the content of hypericin in their formulation owing to the primal assumption that this component determines biologic activity of the extract. We quantified the amount of hyperforin (as the sum of hyperforin and adhyperforin) and hypericin (as the sum of hypericin and pseudohypericin) in each formulation by HPLC. As summarized in Table 1 and depicted in Supplemental Figs. 3 and 4, all formulations contained hypericin, but hyperforin was detected in all medications but Vogel Hyperimed and Vogel Hyperiforce and to a low extent in Rebalance and Remotiv. Importantly, these four medications neither interacted with OATP2B1-mediated $\mathrm{E}_{1} \mathrm{~S}$ accumulation nor did they transactivate CYP3A4 in the cell-based 


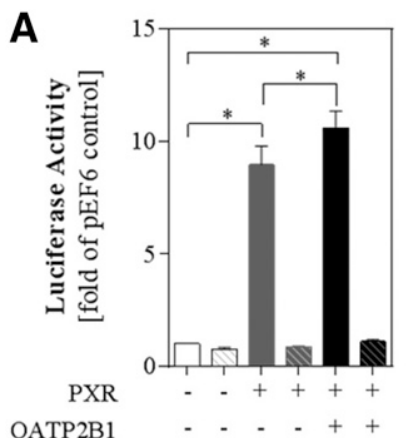

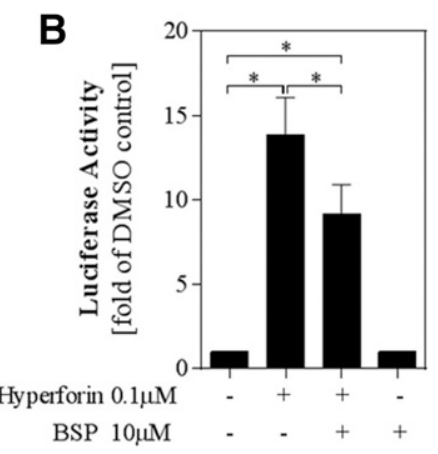

Fig. 2. Influence of OATP2B1 on hyperforin-induced PXR-mediated transactivation of CYP3A4. Luciferase activation was determined in HepG2 cells transfected with PXR-pEF6 in presence or absence of heterologously expressed OATP2B1 and treated with $0.1 \mu \mathrm{M}$ hyperforin or DMSO (striped bars) (A). The influence of bromosulfophthalein on hyperforin-induced PXR activation was assessed in HepG2 cells transiently transfected with PXR-pEF6 and OATP2B1-pEF6 (B). Firefly luciferase activity was normalized to that of Renilla. Data are presented as mean \pm S.D. of $n=3$ independent experiments each performed in biologic triplicates. ${ }^{*} P$-value $\leq 0.05$, two-way analysis of variance with Tukey's multiple comparisons test.

reporter gene assays reported herein, suggesting that hyperforin is the key determinant of the observed effects. To test this notion, we analyzed whether the relationship between hyperforin content and the observed luciferase activation assessed in transfected HepG2 (Fig. 5A) or HeLa cells (Fig. 5B) revealed a direct correlation. The association as determined by Pearson correlation was most pronounced when Hyperiplant, the formulation containing the highest amount of hyperforin, was excluded. An indirect and statistically significant correlation was observed for the percentage of $\mathrm{E}_{1} \mathrm{~S}$ uptake and hyperforin content in MDCKII-OATP2B1 cells (Fig. 5C). Importantly, no correlation was observed for hypericin and the experimental results (Fig. 5, D-F).

\section{Discussion}

In this study we report that the constituents of St. John's wort-hyperforin and to a lower extent hypericin-are inhibitors of the ubiquitously expressed membrane transporter OATP2B1. Furthermore, CCF experiments suggested that the compounds are not only inhibitors but also substrates of OATP2B1. This was further supported by findings in reporter gene assays, in which OATP2B1 enhanced hyperforin-induced transactivation of CYP3A4, which was reduced in the presence of the competitive inhibitor bromosulfophthalein.

Hyperforin is known especially as a major determinant of drug-drug interactions observed during coadministration of St. John's wort, with the expected result of a pronounced increase in CYP3A4 activity (Willson and Kliewer, 2002). However, the influence of concomitant use of St. John's wort is not limited to CYP3A4-substrates as the underlying mechanism; it is the binding and activation of PXR that finally

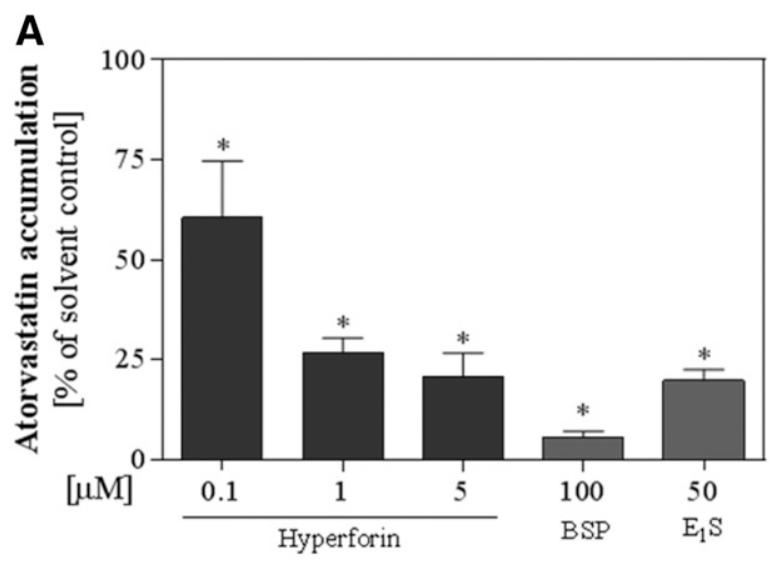

B

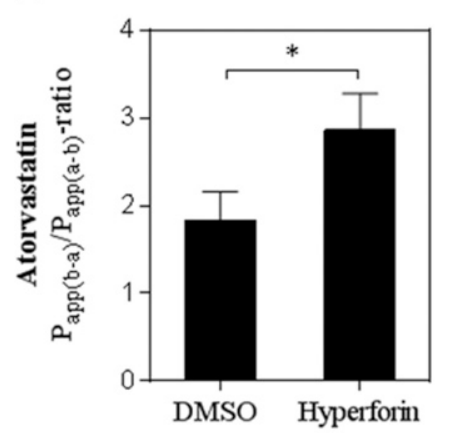

C

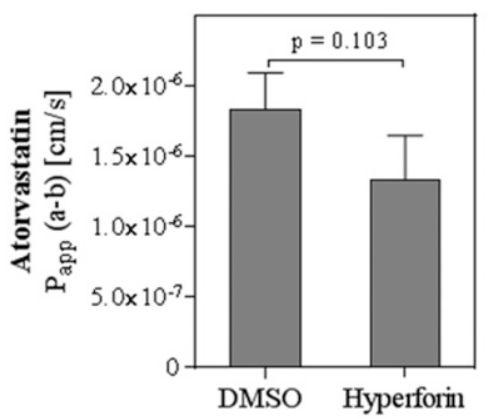

D

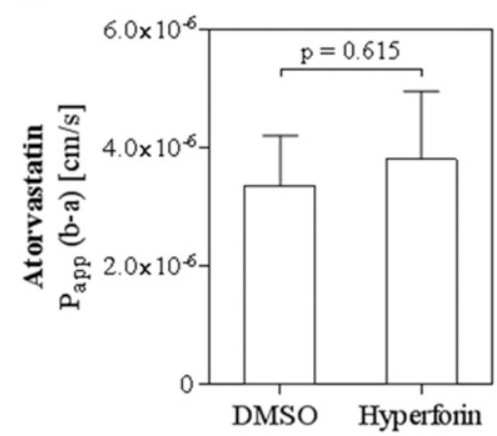

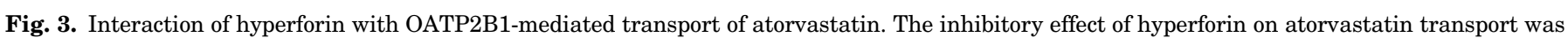

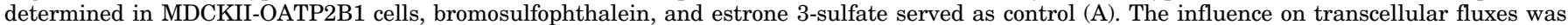

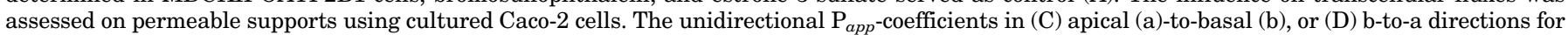

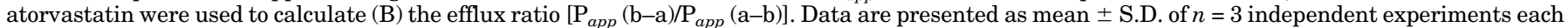
performed in biologic triplicates, ${ }^{*} P \leq 0.05$ one-way analysis of variance with Dunnett's multiple comparisons test (A) or Student's $t$ test (B, C, D). 
TABLE 1

Content of hypericin and hyperforin determined by HPLC-UV

Percentage of hypericin or hyperforin content given in the compendium was converted to content per 100 mg extract. For quantification by HPLC, a standard curve was used to calculate the concentration of hypericin or hyperforin, respectively. Data from quantification are from three independent experiments.

\begin{tabular}{|c|c|c|c|c|c|c|}
\hline \multirow[t]{2}{*}{ Formulation (Tradename) } & \multirow{2}{*}{$\begin{array}{c}\begin{array}{c}\text { Hypericin } \\
\text { (Declared Content) }^{a}\end{array} \\
m g / 100 \mathrm{mg}\end{array}$} & \multicolumn{2}{|c|}{$\begin{array}{c}\text { Hypericin }^{a} \\
\text { (Quantified by HPLC) }\end{array}$} & \multirow{2}{*}{$\begin{array}{c}\text { Hyperforin }^{b} \text { (Declared Content) } \\
m g / 100 \mathrm{mg}\end{array}$} & \multicolumn{2}{|c|}{$\begin{array}{c}\text { Hyperforin }^{b} \\
\text { (Quantified by HPLC) }\end{array}$} \\
\hline & & $\mathrm{mg} / 100 \mathrm{mg}$ & $\pm S . D$ & & $\mathrm{mg} / 100 \mathrm{mg}$ & $\pm S . D$. \\
\hline ARKOCAPS $^{c}$ & 0.3 & 0.09 & \pm 0.04 & - & 0.24 & \pm 0.01 \\
\hline DEPRIVITA $^{d}$ & $0.1-0.3$ & 0.18 & \pm 0.01 & - & 1.04 & \pm 0.05 \\
\hline HAENSELER MENOPAUSE ${ }^{e}$ & $0.1-0.3$ & 0.10 & \pm 0.01 & - & 0.34 & \pm 0.01 \\
\hline HYPERIPLANT ${ }^{f}$ & $0.1-0.3$ & 0.15 & \pm 0.02 & 36 & 1.62 & \pm 0.03 \\
\hline JARSIN $^{g}$ & $0.1-0.3$ & 0.20 & \pm 0.02 & - & 0.70 & \pm 0.02 \\
\hline REBALANCE $^{h}$ & $0.1-0.3$ & 0.08 & \pm 0.01 & $<0.2$ & 0.02 & \pm 0.01 \\
\hline REMOTIV $^{h}$ & $0.1-0.3$ & 0.09 & \pm 0.01 & $<0.2$ & 0.02 & \pm 0.01 \\
\hline SANDOZ HYPERICUM $^{i}$ & $0.1-0.3$ & 0.21 & \pm 0.02 & - & 0.85 & \pm 0.04 \\
\hline SOLEVITA $^{d}$ & $0.1-0.3$ & 0.16 & \pm 0.03 & - & 1.02 & \pm 0.07 \\
\hline VOGEL HYPERIMED $^{j}$ & $0.5-0.8$ & 0.08 & \pm 0.01 & - & - & - \\
\hline VOGEL HYPERIFORCE ${ }^{j}$ & $0.2-2.1$ & 0.08 & \pm 0.01 & - & - & - \\
\hline
\end{tabular}

${ }^{a}$ The content of hypericin corresponds to the sum of the content of hypericin and pseudohypericin.

${ }^{b}$ The content of hyperforin corresponds to the sum of the content of hyperforin and adhyperforin.

${ }^{c}$ Arko Diffusion SA, Les Avacias, Switzerland.

${ }^{d}$ Permamed AG, Therwil, Switzerland.

${ }^{e}$ Hänseler AG, Herisau, Switzerland.

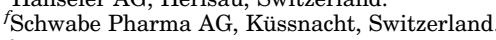

${ }^{g}$ Vifor SA, Bern, Switzerland.

${ }^{h}$ Zeller AG, Romanshorn, Switzerland.

${ }^{i}$ Sandoz Pharmaceuticals AG, Holzkirchen, Germany.

${ }^{j}$ Bioforce AG, Roggwil, Switzerland.

results in induced expression of multiple target genes, most of them with functions in drug elimination (Tolson and Wang, 2010). Indeed, one compound exemplifying this is the cardiac glycoside digoxin (Johne et al., 1999). This drug is commonly used in clinics and is not a CYP3A4 substrate (Lacarelle et al., 1991), but findings by Greiner et al. (1999) clearly showed that concomitant oral intake of digoxin and rifampin decreased drug disposition and exposure owing to induction of P-glycoprotein (P-gp, ABCB1, MDR1) expression. Importantly, rifampin is another well known activating ligand of PXR and can be applied to analyze the influence of PXR activation on drug metabolism (Chen and Raymond, 2006). Accordingly, the reduction in oral bioavailability of digoxin can be explained by enhanced expression of ABCB1 (Greiner et al., 1999). This transporter is responsible for active extrusion of substrates from enterocytes back into the intestinal lumen (Shapiro and Ling, 1995). Considering our findings on inhibition of OATP2B1-mediated transport by hyperforin and hypericin, the interaction of St. John's wort is extended to a further class of compounds, namely OATP2B1 substrates, whose mechanism of interaction would most probably be the competitive inhibition of cellular uptake.

OATP2B1 is assumed to play a role in intestinal absorption of orally administered drugs (Shitara et al., 2013). Testing the influence of hyperforin on transcellular transport of atorvastatin revealed an enhanced efflux ratio for atorvastatin. The experimental setup of Caco- 2 cells cultured on permeable supports is commonly utilized for predictions of bioavailability and the contribution of transporters to intestinal absorption (Hubatsch et al., 2007). Indeed, when an efflux ratio, which is calculated relating the net flux in b-to-a direction with that in a-to-b direction, is above 1.5, it is assumed to indicate that active transporter-mediated processes are involved in the transcellular transport of a compound (Hubatsch et al., 2007). From the results of our study, one is certainly tempted to attribute the observed effect of an enhanced efflux ratio to the inhibition of OATP2B1 only. However, what was assessed were net fluxes, and even though it has been reported as an OATP2B1 substrate (Grube et al., 2006), atorvastatin is not a specific substrate of this transporter. Indeed, atorvastatin is also a substrate of the efflux transporters multidrug resistance-associated protein (MRP)1 (ABCC1), MRP4 (ABCC4), MRP5 (ABCC5) (Knauer et al., 2010), and ABCB1 (Wu et al., 2000). Especially for ABCB1, some data suggest that hyperforin may influence transport activity directly (Hennessy et al., 2002). Our data suggest that, when present, hyperforin acutely interacts with oral absorption of OATP2B1 substrates, enhancing the complexity of drug-hyperforin interactions that should be considered when evaluating the interaction potential of St. John's wort preparations.

In addition to its involvement in intestinal drug absorption, OATP2B1 is assumed to contribute to the hepatocellular uptake. Recent findings by Lutz et al. (2018) suggest that there is at least some induction of OATP-mediated transport, as observed for concomitant treatment with rosuvastatin and pravastatin and increasing doses of rifampin. Even if OATP2B1 (OATP-B) may contribute to the hepatocellular uptake of these statins (Knauer et al., 2010; Shirasaka et al., 2010), OATP2B1 is not regulated in primary human hepatocytes treated with the PXR-inducer (Jigorel et al., 2006). Although there was no direct regulation by PXR, we recently reported interaction of the transporter with $\mathrm{PDZ}$ domain containing 1 (PDZK1), which influences OATP2B1 membrane localization (Ferreira et al., 2018). PDZK1 is transcriptionally controlled by multiple nuclear receptors (Ferreira et al., 2018; Prestin et al., 2017). Accordingly, whether long-term exposure to hyperforin influences localization of OATP2B1 remains to be determined, as we only tested the acute influence. Our findings suggest that the intracellular abundance of hyperforin, and thereby PXR-mediated transactivation of CYP3A4, is influenced by OATP2B1. Considering this finding, one might speculate that changes in OATP2B1 activity could influence the extent of PXR activation. Multiple mechanisms affect the activity of a transporter, and one possibility is the 
A

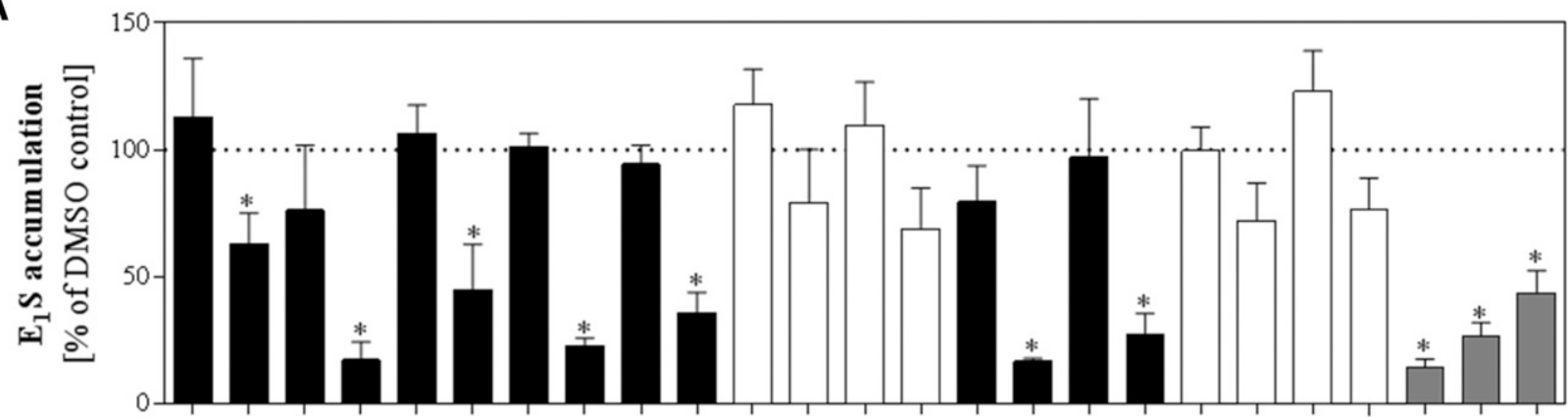

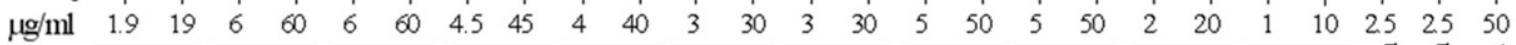

$\overline{\text { Arkocaps }} \frac{\overline{\text { Deprivita }}}{\text { Hänseler Hyperiplant Jarsin Rebalance Remotiv }} \frac{\mathrm{Sandoz}}{\text { Solevita }} \frac{2}{\text { Vogel } 1} \frac{1}{\text { Vogel } 2}$

B

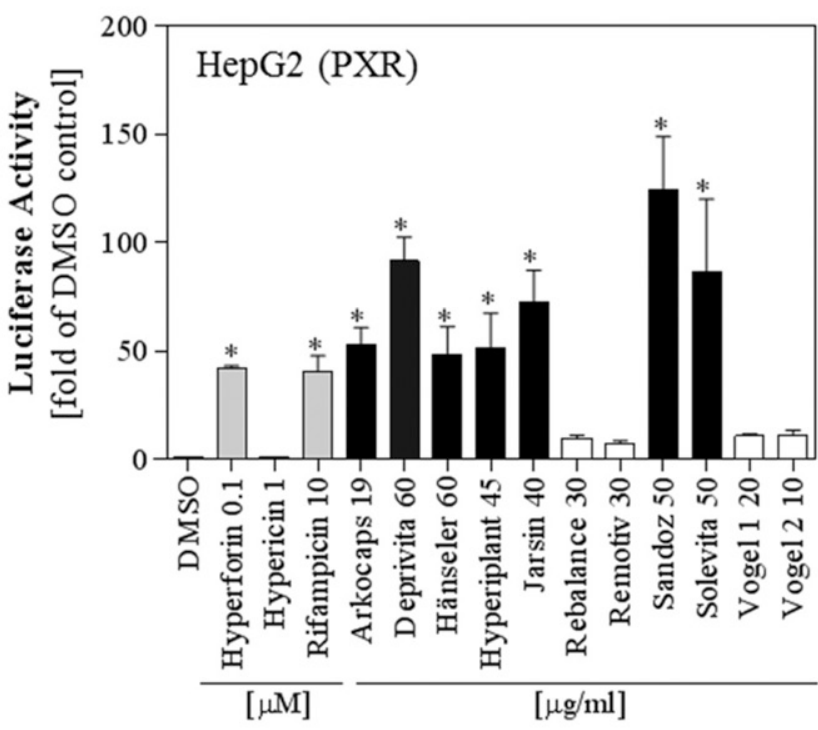

D

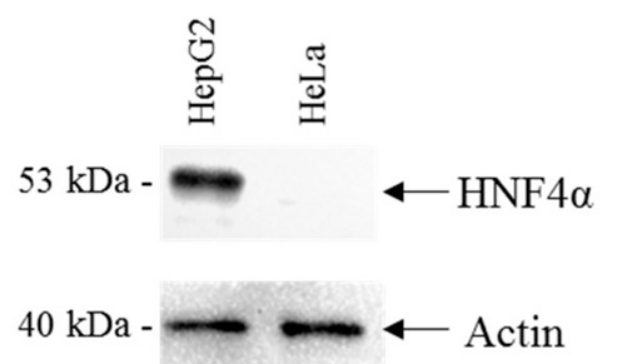

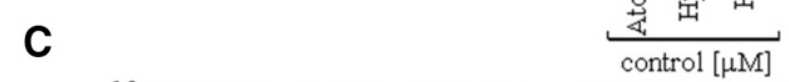

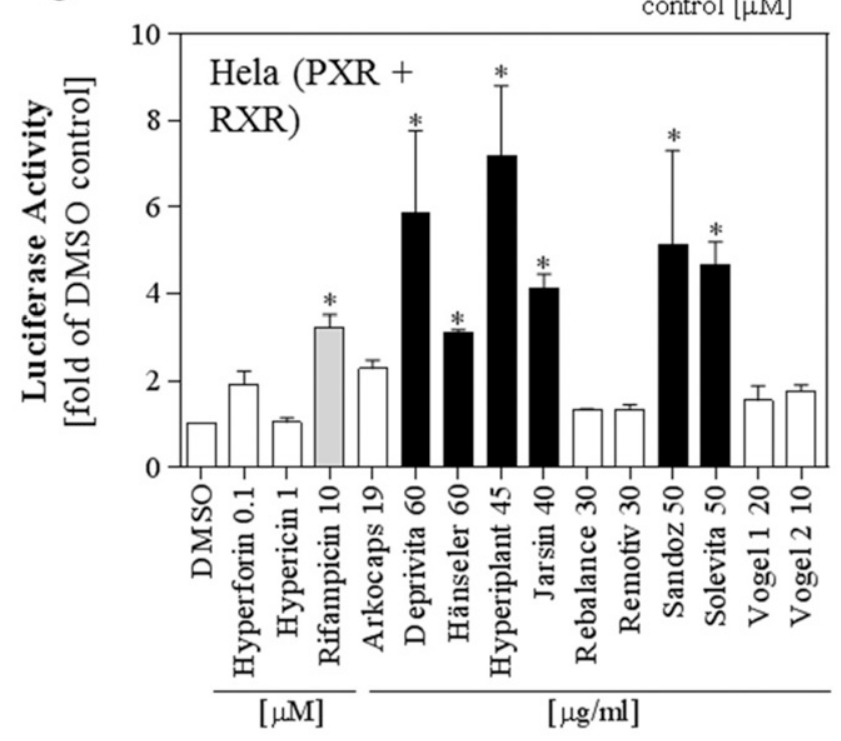

E

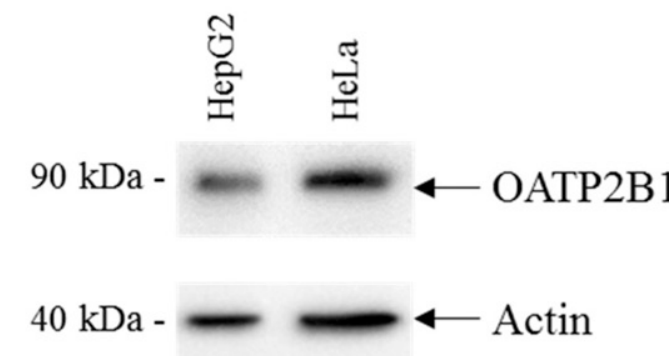

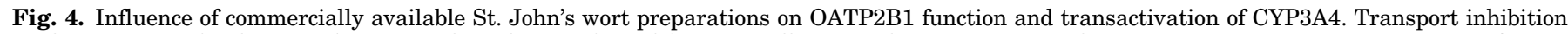

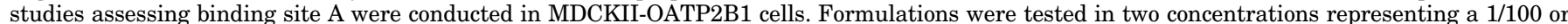

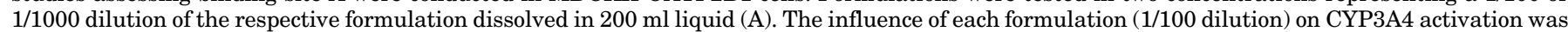

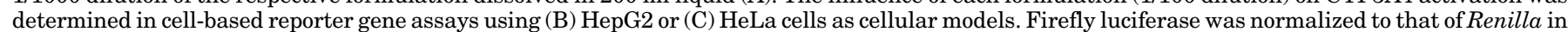

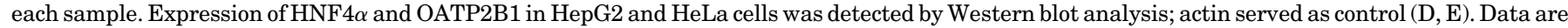

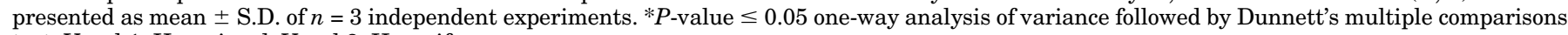
test; Vogel 1, Hyperimed; Vogel 2, Hyperiforce.

change in expression by transcriptional modifiers. Another would be modifications in genetic information with influence on transport activity. We recently reported that OATP2B1 is transcriptionally modulated by thyroid hormones (Meyer zu Schwabedissen et al., 2018), thereby associating thyroid hormone status to OATP2B1 transport function, and Nozawa et al. (2002) identified genetic polymorphisms that changed the maximal transport velocity $\left(\mathrm{V}_{\max }\right)$ of OATP2B1.

Testing extracts from all oral formulations of St. John's wort currently marketed in Switzerland for their influence on OATP2B1 transport activity, and the influence of OATP2B1 on their transactivating activity, revealed a clear association 
A

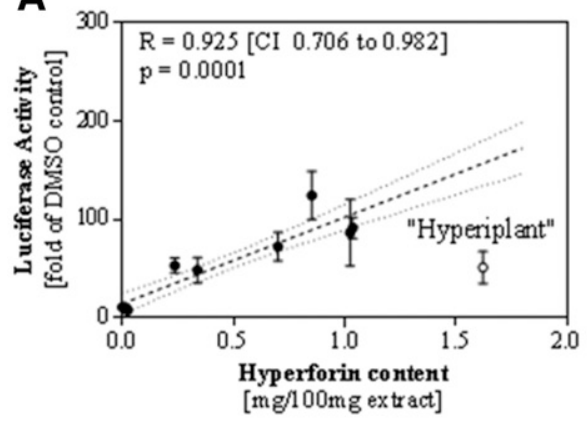

D

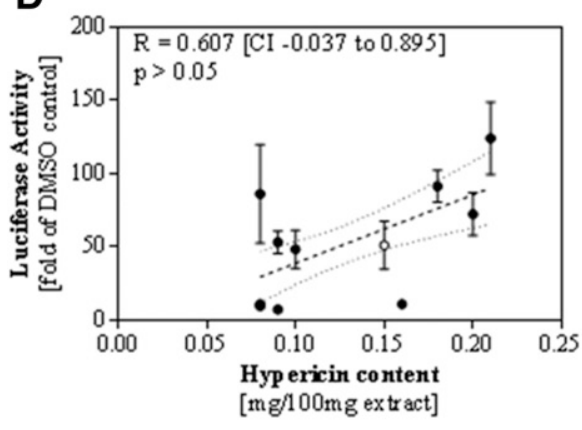

HepG2
B

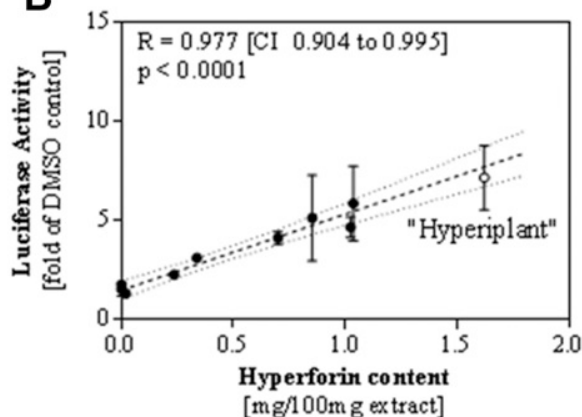

E

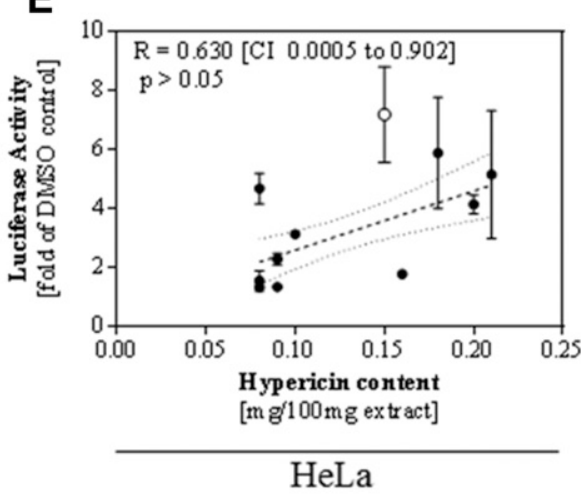

C

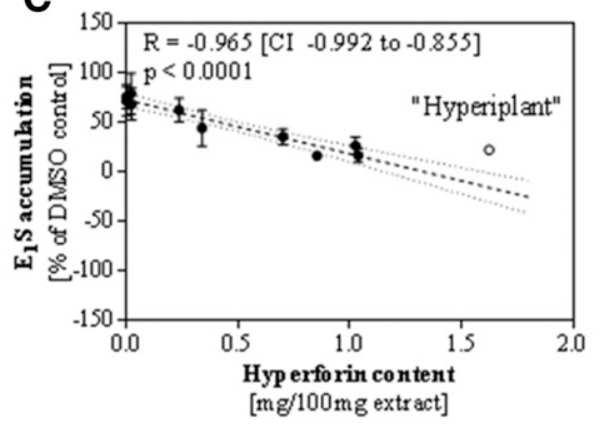

$\mathbf{F}$

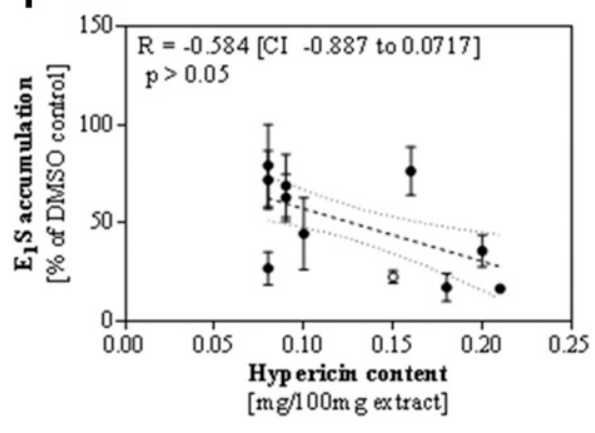

MDCKII-OATP2B1

Fig. 5. Association of hyperforin or hypericin content with the observed effects in cell-based reporter gene assays, or transport inhibition studies. Luciferase activity was determined in transiently transfected HepG2 (A, D) or HeLa cells (B, E). Inhibition studies were conducted in MDCKII stably expressing OATP2B1 (C, F). Association of the observed effect with hyperforin or hypericin content was analyzed by linear regression (indicated by dotted line, shown with confidence interval), correlation was determined by calculating the Pearson coefficient. Data are presented as mean \pm S.D. with results of $n=3$ independent experiments performed in biologic triplicates. R, Pearson coefficient; open symbol indicated "Hyperiplant", which was neither included in the linear regression nor the calculation of the Pearson coefficient.

between hyperforin content and the observed effect for most formulations. Importantly, no such association was observed for hypericin content and PXR-mediated transactivation, thus confirming that hypericin is no activator of PXR (Moore et al., 2000; Wentworth et al., 2000). Furthermore, there is no clear association of hypericin content and OATP2B1 inhibition, which is in line with the much lower inhibitory potency observed for hypericin compared with hyperforin. This indicates that hyperforin is the component of St. John's wort extracts involved in interaction with OATP2B1-mediated uptake.

The formulations were tested in cell-based reporter gene assays using HepG2 or HeLa cells as cellular models. In the liver cell model we observed a huge induction of luciferase activity of about 50- to 100-fold, whereas the increase in activity was only about 5- to 7-fold in HeLa cells, with some formulations not affecting transactivation. On the one hand, the difference in extent of activation might certainly be explained by endogenous expression of HNF4 $\alpha$ in HepG2 cells, which is not present in HeLa cells as confirmed by Western blot analysis in this study and previously reported by Knauer et al. (2013). Importantly, HNF4 $\alpha$ is permissive for the transcriptional regulation by PXR (Ma et al., 2008). On the other hand, the fact that we observed induction in HeLa cells and a clear association of the extent of activation with the hyperforin content suggests that hyperforin is the driving component, but also that there is at least some HNF $4 \alpha$ independent PXR activation.

As mentioned before, the hyperforin content was directly correlated with the observed luciferase activation. However, this association was most pronounced when Hyperiplant was excluded from the correlation. In other words, the observed effect of Hyperiplant on OATP2B1-mediated transport or CYP3A4 activation was lower than expected considering the hyperforin content. In this context, it seems noteworthy that hyperforin is phototoxic (Onoue et al., 2011), inducing acute cell lysis. Even though our experiments were conducted under light protection, we cannot exclude the presence of some toxicity that could have modified the experimental outcome.

Taken together we report that hyperforin is a potent inhibitor of OATP2B1-mediated cellular uptake and we suggest that it is also a substrate. Inhibition of the transporter may influence the contribution of OATP2B1 to pharmacokinetics of its substrate drugs. Moreover, OATP2B1 activity influences intracellular accumulation of hyperforin and thereby its binding to the xenosensor. With this study, we added to the complexity of potential mechanisms that should be included in the evaluation of potential drug-drug interactions associated with the dispensing of St. John's wort.

\section{Acknowledgments}

The study reported herein will be part of the thesis of A.M.S.

\section{Authorship Contributions}

Participated in research design: Schäfer, Potterat, Meyer zu Schwabedissen.

Conducted experiments: Schäfer, Potterat, Seibert, Fertig, Meyer zu Schwabedissen.

Contributed new reagents or analytic tools: Potterat, Meyer zu Schwabedissen. 
Performed data analysis: Schäfer, Potterat, Meyer zu Schwabedissen.

Wrote or contributed to the writing of the manuscript: Schäfer, Potterat, Seibert, Fertig, Meyer zu Schwabedissen.

\section{References}

Aleksunes LM and Klaassen CD (2012) Coordinated regulation of hepatic phase I and II drug-metabolizing genes and transporters using AhR-, CAR-, PXR-, PPAR $\alpha$-, and Nrf2-null mice. Drug Metab Dispos 40:1366-1379.

Bronger H, König J, Kopplow K, Steiner HH, Ahmadi R, Herold-Mende C, Keppler D, and Nies AT (2005) ABCC drug efflux pumps and organic anion uptake transporters in human gliomas and the blood-tumor barrier. Cancer Res 65 $11419-11428$.

Chen J and Raymond K (2006) Roles of rifampicin in drug-drug interactions: underlying molecular mechanisms involving the nuclear pregnane $\mathrm{X}$ receptor. Ann Clin Microbiol Antimicrob 5:3.

Dürr D, Stieger B, Kullak-Ublick GA, Rentsch KM, Steinert HC, Meier PJ, and Fattinger K (2000) St John's wort induces intestinal P-glycoprotein/MDR1 and intestinal and hepatic CYP3A4. Clin Pharmacol Ther 68:598-604.

Ferreira C, Hagen P, Stern M, Hussner J, Zimmermann U, Grube M, and Meyer Zu Schwabedissen HE (2018) The scaffold protein PDZK1 modulates expression and function of the organic anion transporting polypeptide 2B1. Eur J Pharm Sci 120 181-190.

Ferreira C, Prestin K, Hussner J, Zimmermann U, and Meyer Zu Schwabedissen HE (2018) PDZ domain containing protein 1 (PDZK1), a modulator of membrane proteins, is regulated by the nuclear receptor THR $\beta$. Mol Cell Endocrinol 461 $215-225$

Geick A, Eichelbaum M, and Burk O (2001) Nuclear receptor response elements mediate induction of intestinal MDR1 by rifampin. $J$ Biol Chem 276 14581-14587.

Greiner B, Eichelbaum M, Fritz P, Kreichgauer HP, von Richter O, Zundler J, and Kroemer HK (1999) The role of intestinal P-glycoprotein in the interaction of digoxin and rifampin. $J$ Clin Invest 104:147-153.

Grube M, Köck K, Oswald S, Draber K, Meissner K, Eckel L, Böhm M, Felix SB Vogelgesang S, Jedlitschky G, et al. (2006) Organic anion transporting polypeptide 2B1 is a high-affinity transporter for atorvastatin and is expressed in the human heart. Clin Pharmacol Ther 80:607-620.

Grube M, Meyer Zu Schwabedissen H, Draber K, Präger D, Möritz KU, Linnemann K, Fusch C, Jedlitschky G, and Kroemer HK (2005) Expression, localization, and function of the carnitine transporter octn2 (slc22a5) in human placenta. Drug Metab Dispos 33:31-37.

Harper JN and Wright SH (2013) Multiple mechanisms of ligand interaction with the human organic cation transporter, OCT2. Am J Physiol Renal Physiol 304: F56-F67

Hennessy M, Kelleher D, Spiers JP, Barry M, Kavanagh P, Back D, Mulcahy F, and Feely J (2002) St Johns wort increases expression of P-glycoprotein: implications for drug interactions. Br J Clin Pharmacol 53:75-82.

Hubatsch I, Ragnarsson EG, and Artursson P (2007) Determination of drug permeability and prediction of drug absorption in Caco-2 monolayers. Nat Protoc 2 2111-2119.

Jigorel E, Le Vee M, Boursier-Neyret C, Parmentier Y, and Fardel O (2006) Differential regulation of sinusoidal and canalicular hepatic drug transporter expression by xenobiotics activating drug-sensing receptors in primary human hepatocytes. Drug Metab Dispos 34:1756-1763.

Johne A, Brockmöller J, Bauer S, Maurer A, Langheinrich M, and Roots I (1999) Pharmacokinetic interaction of digoxin with an herbal extract from St John's wort (Hypericum perforatum). Clin Pharmacol Ther 66:338-345.

Keiser M, Kaltheuner L, Wildberg C, Müller J, Grube M, Partecke LI, Heidecke CD, and Oswald S (2017) The organic anion-transporting peptide 2B1 is localized in the basolateral membrane of the human jejunum and Caco-2 monolayers. J Pharm Sci 106:2657-2663.

Kliewer SA, Goodwin B, and Willson TM (2002) The nuclear pregnane X receptor: a key regulator of xenobiotic metabolism. Endocr Rev 23:687-702.

Knauer MJ, Girdwood AJ, Kim RB, and Tirona RG (2013) Transport function and transcriptional regulation of a liver-enriched human organic anion transporting polypeptide 2B1 transcriptional start site variant. Mol Pharmacol 83:1218-1228. Knauer MJ, Urquhart BL, Meyer zu Schwabedissen HE, Schwarz UI, Lemke CJ, Leake BF, Kim RB, and Tirona RG (2010) Human skeletal muscle drug transporters determine local exposure and toxicity of statins. Circ Res $\mathbf{1 0 6}$ 297-306

Kobayashi D, Nozawa T, Imai K, Nezu J, Tsuji A, and Tamai I (2003) Involvement of human organic anion transporting polypeptide OATP-B (SLC21A9) in $\mathrm{pH}$-dependent transport across intestinal apical membrane. J Pharmacol Exp Ther 306:703-708.

Kullak-Ublick GA, Ismair MG, Stieger B, Landmann L, Huber R, Pizzagalli F, Fattinger K, Meier PJ, and Hagenbuch B (2001) Organic anion-transporting polypeptide B (OATP-B) and its functional comparison with three other OATPs of human liver. Gastroenterology 120:525-533.

Lacarelle B, Rahmani R, de Sousa G, Durand A, Placidi M, and Cano JP (1991) Metabolism of digoxin, digoxigenin digitoxosides and digoxigenin in human hepatocytes and liver microsomes. Fundam Clin Pharmacol 5 $567-582$.

Lehmann JM, McKee DD, Watson MA, Willson TM, Moore JT, and Kliewer SA (1998) The human orphan nuclear receptor PXR is activated by compounds that regulate CYP3A4 gene expression and cause drug interactions. J Clin Invest 102 $1016-1023$

Lutz JD, Kirby BJ, Wang L, Song Q, Ling J, Massetto B, Worth A, Kearney BP, and Mathias A (2018) Cytochrome P450 3A induction predicts P-glycoprotein induction; part 1: establishing induction relationships using ascending dose rifampin. Clin Pharmacol Ther 104:1182-1190.

Ma X, Cheung C, Krausz KW, Shah YM, Wang T, Idle JR, and Gonzalez FJ (2008) A double transgenic mouse model expressing human pregnane $\mathrm{X}$ receptor and cytochrome P450 3A4. Drug Metab Dispos 36:2506-2512.

Mennini T and Gobbi M (2004) The antidepressant mechanism of Hypericum perforatum. Life Sci 75:1021-1027.

Meyer Zu Schwabedissen HE, Ferreira C, Schaefer AM, Oufir M, Seibert I, Hamburger M, and Tirona RG (2018) Thyroid hormones are transport substrates and transcriptional regulators of organic anion transporting polypeptide 2B1. Mol Pharmacol 94:700-712.

Meyer zu Schwabedissen HE and Kim RB (2009) Hepatic OATP1B transporters and nuclear receptors PXR and CAR: interplay, regulation of drug disposition genes, and single nucleotide polymorphisms. Mol Pharm 6:1644-1661.

Meyer zu Schwabedissen HE, Tirona RG, Yip CS, Ho RH, and Kim RB (2008) Interplay between the nuclear receptor pregnane $\mathrm{X}$ receptor and the uptake transporter organic anion transporter polypeptide 1A2 selectively enhances estrogen effects in breast cancer. Cancer Res 68:9338-9347.

Moore LB, Goodwin B, Jones SA, Wisely GB, Serabjit-Singh CJ, Willson TM, Collins JL, and Kliewer SA (2000) St. John's wort induces hepatic drug metabolism through activation of the pregnane X receptor. Proc Natl Acad Sci USA 97: $7500-7502$

Nahrstedt A and Butterweck V (1997) Biologically active and other chemical constituents of the herb of Hypericum perforatum L. Pharmacopsychiatry 30 (Suppl 2): 129-134

Niessen J, Jedlitschky G, Grube M, Bien S, Schwertz H, Ohtsuki S, Kawakami H, Kamiie J, Oswald S, Starke K, et al. (2009) Human platelets express organic aniontransporting peptide 2B1, an uptake transporter for atorvastatin. Drug Metab Dispos 37:1129-1137.

Nozawa T, Nakajima M, Tamai I, Noda K, Nezu J, Sai Y, Tsuji A, and Yokoi T (2002) Genetic polymorphisms of human organic anion transporters OATP-C (SLC21A6) and OATP-B (SLC21A9): allele frequencies in the Japanese population and functional analysis. J Pharmacol Exp Ther 302:804-813.

Onoue S, Seto Y, Ochi M, Inoue R, Ito H, Hatano T, and Yamada S (2011) In vitro photochemical and phototoxicological characterization of major constituents in St. John's wort (Hypericum perforatum) extracts. Phytochemistry 72:1814-1820.

Piscitelli SC, Burstein AH, Chaitt D, Alfaro RM, and Falloon J (2000) Indinavir concentrations and St John's wort. Lancet 355:547-548.

Pizzagalli F, Varga Z, Huber RD, Folkers G, Meier PJ, and St-Pierre MV (2003) Identification of steroid sulfate transport processes in the human mammary gland. $J$ Clin Endocrinol Metab 88:3902-3912.

Prestin K, Hussner J, Ferreira C, Seibert I, Breitung V, Zimmermann U, and Meyer $\mathrm{Zu}$ Schwabedissen HE (2017) Regulation of PDZ domain-containing 1 (PDZK1) expression by hepatocyte nuclear factor-1 $\alpha$ (HNF1 $\alpha)$ in human kidney. Am $J$ Physiol Renal Physiol 313:F973-F983.

Roth M, Obaidat A, and Hagenbuch B (2012) OATPs, OATs and OCTs: the organic anion and cation transporters of the SLCO and SLC22A gene superfamilies. $\mathrm{Br} J$ Pharmacol 165:1260-1287.

Ruschitzka F, Meier PJ, Turina M, Lüscher TF, and Noll G (2000) Acute heart transplant rejection due to Saint John's wort. Lancet 355:548-549.

Sakamoto A, Matsumaru T, Yamamura N, Uchida Y, Tachikawa M, Ohtsuki S, and Terasaki T (2013) Quantitative expression of human drug transporter proteins in lung tissues: analysis of regional, gender, and interindividual differences by liquid chromatography-tandem mass spectrometry. J Pharm Sci 102:3395-3406.

Schäfer AM, Bock T, and Meyer Zu Schwabedissen HE (2018) Establishment and validation of competitive counterflow as a method to detect substrates of the organic anion transporting polypeptide 2B1. Mol Pharm 15:5501-5513.

Schiffer R, Neis M, Höller D, Rodríguez F, Geier A, Gartung C, Lammert F, Dreuw A Zwadlo-Klarwasser G, Merk H, et al. (2003) Active influx transport is mediated by members of the organic anion transporting polypeptide family in human epiderma keratinocytes. J Invest Dermatol 120:285-291.

Shapiro AB and Ling V (1995) Reconstitution of drug transport by purified P-glycoprotein. J Biol Chem 270:16167-16175.

Shirasaka Y, Mori T, Shichiri M, Nakanishi T, and Tamai I (2012) Functional pleiotropy of organic anion transporting polypeptide OATP2B1 due to multiple binding sites. Drug Metab Pharmacokinet 27:360-364.

Shirasaka Y, Suzuki K, Nakanishi T, and Tamai I (2010) Intestinal absorption of HMG-CoA reductase inhibitor pravastatin mediated by organic anion transporting polypeptide. Pharm Res 27:2141-2149.

Shitara Y, Maeda K, Ikejiri K, Yoshida K, Horie T, and Sugiyama Y (2013) Clinical significance of organic anion transporting polypeptides (OATPs) in drug disposition: their roles in hepatic clearance and intestinal absorption. Biopharm Drug Dispos 34:45-78

Soleymani S, Bahramsoltani R, Rahimi R, and Abdollahi M (2017) Clinical risks of St John's wort (Hypericum perforatum) co-administration. Expert Opin Drug Metab Toxicol 13:1047-1062.

St-Pierre MV, Hagenbuch B, Ugele B, Meier PJ, and Stallmach T (2002) Characterization of an organic anion-transporting polypeptide (OATP-B) in human placenta. J Clin Endocrinol Metab 87:1856-1863.

Suzuki O, Katsumata Y, Oya M, Bladt S, and Wagner H (1984) Inhibition of monoamine oxidase by hypericin. Planta Med 50:272-274.

Tamai I, Nezu J, Uchino H, Sai Y, Oku A, Shimane M, and Tsuji A (2000) Molecular identification and characterization of novel members of the human organic anion transporter (OATP) family. Biochem Biophys Res Commun 273:251-260.

Tirona RG, Lee W, Leake BF, Lan LB, Cline CB, Lamba V, Parviz F, Duncan SA, Inoue Y, Gonzalez FJ, et al. (2003) The orphan nuclear receptor HNF4alpha determines PXR- and CAR-mediated xenobiotic induction of CYP3A4. Nat Med $\mathbf{9}$ $220-224$

Tolson AH and Wang H (2010) Regulation of drug-metabolizing enzymes by xenobiotic receptors: PXR and CAR. Adv Drug Deliv Rev 62:1238-1249. 
Wang Z, Lin YS, Dickmann LJ, Poulton EJ, Eaton DL, Lampe JW, Shen DD, Davis CL, Shuhart MC, and Thummel KE (2013) Enhancement of hepatic 4-hydroxylation of 25-hydroxyvitamin D3 through CYP3A4 induction in vitro and in vivo: implications for drug-induced osteomalacia. $J$ Bone Miner Res 28: 1101-1116.

Wentworth JM, Agostini M, Love J, Schwabe JW, and Chatterjee VK (2000) St John's wort, a herbal antidepressant, activates the steroid X receptor. J Endocrinol 166 R11-R16.

Willson TM and Kliewer SA (2002) PXR, CAR and drug metabolism. Nat Rev Drug Discov 1:259-266.
Wu X, Whitfield LR, and Stewart BH (2000) Atorvastatin transport in the Caco-2 cell model: contributions of P-glycoprotein and the proton-monocarboxylic acid co-transporter. Pharm Res 17:209-215.

Address correspondence to: Dr. Henriette E. Meyer zu Schwabedissen, Biopharmacy, Department of Pharmaceutical Sciences, University of Basel, Klingelbergstrasse 50, 4056 Basel, Switzerland. E-mail: h.meyerzuschwabedissen@ unibas.ch 